\title{
Case - Severely oligozoospermic patient with both mosaic Klinefelter syndrome and a complete AZFc Y chromosome microdeletion
}

\author{
Andrew Golin ${ }^{1}$; Sarah Neil ${ }^{4}$; Ryan Flannigan ${ }^{3,4}$ \\ ${ }^{1}$ Faculty of Medicine, University of British Columbia, Vancouver, BC, Canada; ${ }^{2}$ Olive Fertility Centre, Vancouver, \\ BC, Canada; ${ }^{3}$ Department of Urologic Sciences, University of British Columbia, Vancouver, BC, Canada; ${ }^{4}$ Weill \\ Cornell Medicine, Department of Urology, New York, NY, United States
}

Cite as: Can Urol Assoc J 2019 November 29; Epub ahead of print. http://dx.doi.org/10.5489/cuaj.6255

Published online November 29, 2019

$* * *$

\section{Introduction}

Klinefelter syndrome (KS) is the most prevalent sex chromosome disorder in males and is the most common genetic cause of male infertility. ${ }^{1,2}$ First described in 1942 as an endocrine disorder characterized by high follicle-stimulating hormone (FSH) levels, small firm testes, gynecomastia, and hypogonadism. ${ }^{3}$ The most common chromosomal aberration of KS is 47, XXY, where an additional X chromosome is present. The pathogenesis of KS can be explained by non-disjunction in either meiotic divisions during germ-cell development, or in early embryonic mitotic cell divisions. ${ }^{4}$ A subset of KS, mosaic Klinefelter syndrome $(46, X Y / 47, X X Y)$, occurs when the extra X chromosome is only present in a certain proportion of cells. Men with mosaic KS have a higher prognostic value of spermatogenesis than men with non-mosaic KS. ${ }^{5}$

The $\mathrm{Y}$ chromosome is composed of many genes known to drive gonadal differentiation and testicular development. ${ }^{6}$ Despite its importance in creating the male phenotype, the chromosome contains a large proportion of repetitive genetic elements rendering it unstable and prone to deletions, termed Y chromosome microdeletions (YCM). ${ }^{7}$ Microdeletions of a specific region of the $\mathrm{Y}$ chromosome long arm, the azoospermia factor (AZF) locus, are commonly associated with impaired spermatogenesis. After KS, YCM is the second most common genetic cause of male infertility. ${ }^{1}$

The AZF locus can be classified into four intervals (AZFa, AZFb, AZFc, AZFd), where the severity of male infertility is greatest in AZFa deletions and decreases with subsequently deleted intervals. In addition to the specific Y chromosome interval deleted, the severity of infertility phenotypes is correlated to the size of deletion - complete versus partial, and multiple AZF loci (e.g., AZFab) versus classical (single interval deleted) AZF deletions (e.g., AZFa). 
Besides impaired spermatogenesis, men with YCM typically present with higher FSH levels, and inconsistent effects of luteinizing hormone ( $\mathrm{LH})$, testosterone levels, and testicular volume. ${ }^{8}$ The prevalence of YCM varies depending on geographic and ethnic background, but the global prevalence among men with non-obstructive azoospermia has been reported to be approximately 7.6\%. ${ }^{9}$ Given the high prevalence of KS and YCM in non-obstructive azoospermia, it is recommended to test for both during the clinical evaluation of severely oligozoospermic patients.

\section{Case report}

The patient is a 34-year old man who was seen for an infertility evaluation. He had a thirteenmonth history of primary infertility with his 37-year old female partner. Neither the patient nor his partner have had any pregnancies from previous relationships. The patient has an unremarkable surgical, family, and social history pertaining to fertility. His physical exam was unremarkable with no signs of gynecomastia, normal virilization, and of average height. Scrotal physical exam revealed a right and left testicular volume of $12 \mathrm{cc}$ and $10 \mathrm{cc}$, respectively, with normal firmness and normal epididymides bilatrally. Spermatic cord examination revealed no varicoceles and vasa deferens were both felt bilaterally. He is currently using allopurinol to help control his history of gout, though he has had no recent flareups. His partner has had no history of abnormal menstruation, sexually transmitted infections, pelvic inflammatory disease, endometriosis, uterine fibroids, or any abdominal or pelvic surgery.

The patient's hormone panel revealed a normal profile (morning serum total testosterone of $19.3 \mathrm{nmol} / \mathrm{L}$, prolactin of $8.9 \mathrm{ug} / \mathrm{L}$, follicle stimulating hormone $(\mathrm{FSH})$ of $4.4 \mathrm{U} / \mathrm{L}$, luteinizing hormone ( $\mathrm{LH})$ of $2.5 \mathrm{U} / \mathrm{L})$. Three repeated semen analyses revealed severe oligozoospermia/cryptozoospermia ( $\leq 1 \mathrm{million} / \mathrm{ml}$ ) (Table 1). Given this, the man underwent chromosomal analysis and $\mathrm{Y}$ chromosome microdeletion testing. Karyotype results revealed mosaic Klinefelter Syndrome with 46,XY[14 cells], and 47,XXY[11 cells]. Y-chromosome microdeletion testing was also positive for a complete AZFc deletion.

\section{Discussion}

The literature describing the genetic relationship between either mosaic or non-mosaic Klinefelter syndrome and Y chromosome microdeletions is unclear. Certain studies have found no association between $\mathrm{KS}$ and classical $\mathrm{YCM}^{10,11}$ whereas others propose an association. ${ }^{12,13}$ In the aforementioned studies, all patients with either mosaic or non-mosaic KS and a YCM were azoospermic. In this case report, however, we describe an exceptional event where a severely oligozoospermic/cryptozoospermic man was diagnosed with both mosaic Klinefelter syndrome and a complete AZFc Y chromosome microdeletion. To our knowledge, this is the only reported case in the literature where a man with mosaic KS and complete AZFc YCM has sperm in their ejaculate. 
Men with mosaic KS and YCM typically present with high FSH levels and other classical stigmata. ${ }^{3,8}$ Interestingly, these laboratory findings are not present in our patient, and is thus exhibiting a less severe phenotype than what is typical for men with non-mosaic Klinefelter syndrome and a complete AZFc deletion.

This case highlights some of the challenges that arise when counselling patients with mosaic karyotypes, namely the uncertainty that accompanies such a result. It has long been recognized that men with mosaic KS exhibit milder symptoms than those with non-mosaic $\mathrm{KS}^{14}$. Indeed, we describe here a phenotypically normal patient with a normal male hormone profile, and oligospermia. However, a number of men with mosaic KS do exhibit the classic non-mosaic phenotype to some degree, and $75 \%$ of men with mosaic KS are described to be azoospermic. ${ }^{14,15}$ It is important to note that peripheral blood karyotyping is not necessarily reflective of the cell lines present in the tissues responsible for spermatogenesis, and therefore extrapolating prognostic information from these karyotypes must be done with caution. Furthermore, among patients with complete AZFc YCM, approximately $22 \%$ of men will have severe oligozoospermia or cryptozoospermia, while the remainder are azoospermic. However, of the limited studies on combined KS and YCMs, no cases to date have identified sperm in the ejaculate, making this case extremely unique. ${ }^{10,11,12,13}$ This case also encourages further investigations to more clearly determine the relationship between Klinefelter syndrome and Y chromosome microdeletions.

\section{Conclusions}

This case describes a unique event where a man with both mosaic Klinefelter syndrome and a complete AZFc Y chromosome microdeletion was found to be severely oligozoospermic. This case underscores the possibility of identifying sperm in the ejaculate and potential fertility with enough motile sperm to use for intracytoplasmic sperm injection, in a man with both mosaic KS and a complete AZFc YCM, despite all other cases in the literature reporting azoospermia. We recommend that clinicians should consider the possibility of genetic analysis in the work-up of severely oligozoospermic men, recognize the heterogeneity of phenotype despite genetic findings, and appreciate the importance of genetic counselling prior to assisted reproductive technologies. 


\section{References}

1. Krausz C, Hoefsloot L, Simoni M, et al. EAA/EMQN best practice guidelines for molecular diagnosis of Y-chromosomal microdeletions: state-of-the-art 2013. Andrology 2014;2:5-19.

2. Groth KA, Skakkebæk A, Høst C, et al. Clinical review: Klinefelter syndrome--a clinical update. J Clin Endocrinol 2013;98:20-30.

3. Klinefelter HF, Reifenstein EC, Albright F. Syndrome characterized by gynecomastia, aspermatogenesis without Leydigism, increased excretion of follicle stimulating hormone. J Clin Endocrinol 1942;2:615-27

4. Lanfranco F, Kamischke A, Zitzmann M, et al. Klinefelter's syndrome. Lancet 2004;364:273-83.

5. Bergère $M$, Wainer $R$, Nataf $V$, et al. Biopsied testis cells of four $47, X X Y$ patients: fluorescence in-situ hybridization and ICSI results. Hum Reprod 2002;17:32-7.

6. Schlegel PN. The Y chromosome. Reprod Biomed Online 2002;5:22-5.

7. Girardi SK, Mielnik A, Schlegel PN. Submicroscopic deletions in the Y chromosome of infertile men. Hum Reprod 1997;12:1635-41.

8. Ferlin A, Arredi B, Speltra E, et al. Molecular and clinical characterization of Y chromosome microdeletions in infertile men: a 10-year experience in Italy. J Clin Endocrinol Metab 2007;92:762-70.

9. Colaco S, Modi D. Genetics of the human Y chromosome and its association with male infertility. Reprod Biol Endocrinol 2018;16:14.

10. Sciarra F, Pelloni M, Faja F, et al. Incidence of Y chromosome microdeletions in patients with Klinefelter syndrome. J Endocrinol Invest 2019;42:833-42.

11. Choe JH, Kim JW, Lee JS, et al. Routine screening for classical azoospermia factor deletions of the $\mathrm{Y}$ chromosome in azoospermic patients with Klinefelter syndrome. Asian J Androl 2007;9:815-20.

12. Hadjkacem-Loukil L, Ghorbel M, Bahloul A, et al. Genetic association between AZF region polymorphism and Klinefelter syndrome. Reprod Biomed Online 2009;19:547-51.

13. Mitra A, Dada R, Kumar R, et al. Y chromosome microdeletions in azoospermic patients with Klinefelter's syndrome. Asian J Androl 2006;8:81-8.

14. Samplaski MK, Lo KC, Grober ED, et al. Phenotypic differences in mosaic Klinefelter patients as compared with non-mosaic Klinefelter patients. Fertility and Sterility 2014;101:950-5.

15. Mau-Holzmann U. Somatic chromosomal abnormalities in infertile men and women. Cytogenet Genome Res 2005;111:317-36. 


\section{Figures and Tables}

\begin{tabular}{|l|c|c|c|}
\hline Table 1. Semen analyses during infertility evaluations & March 2019 \\
\hline Laboratory result & October 2018 & December 2018 & 0.7 \\
\hline Volume (ml) & 3.4 & 3.8 & $<1$ \\
\hline $\begin{array}{l}\text { Sperm concentration } \\
\text { (million/ml) }\end{array}$ & $<1$ & $<1$ & NP* $^{* *}$ \\
\hline Motility (\%) & 8 & $\mathrm{NP}^{*}$ & $\mathrm{NP}^{*}$ \\
\hline $\begin{array}{l}\text { Total motile sperm } \\
\text { count (million) }\end{array}$ & 0.272 & $\mathrm{NP}^{*}$ & 39 \\
\hline $\begin{array}{l}\text { Progressive motility } \\
\text { (\%) }\end{array}$ & 2 & $\mathrm{NP}^{*}$ & $\mathrm{NP}^{*}$ \\
\hline $\begin{array}{l}\text { Morphology (normal } \\
\text { forms, \%; immature } \\
\text { forms, /100 sperm) }\end{array}$ & $\mathrm{NP}^{*}$ & & \\
\hline
\end{tabular}

$\mathrm{NP}^{*}$ : not possible to calculate due to low sperm concentration. ${ }^{* *}$ In whole Makler chamber: 13 progressive motility, 2 non-progressive motility, 18 non-motile. 